\title{
PEMBUATAN SABUN CAIR CUCI PIRING BERBASIS SURFAKTAN SODIUM LOURYL SULFATE
}

\author{
Dahliani Silvia Sianiar $^{1}$, Ni Luh Gede Ratna juliasih", Agung Abadi Kiswandono ${ }^{1 *}$ \\ ${ }^{1}$ Jurusan Kimia, Fakultas Matematika dan ilmu Pengetahuan Alam, Universitas Lampung \\ Bandar Lampung 35141
}

agung.abadi@fmipa.unila.ac.id

Artikel Info
$\begin{aligned} & \text { Diterima } \\ & \text { tanggal } \\ & 25.09 .2021\end{aligned}$
Disetujui
publikasi
tanggal
20.10.2021
Kata kunci :
Sabun Cair,
Surfaktan,
Sodium Louryl
Sulfate

\section{ABSTRAK}

Penggunaan sabun untuk kalangan rumah tangga sangat banyak diantaranya sabun cair cuci piring, sabun cair cuci piring adalah satu bahan pokok yang sangat dibutuhkan untuk membersihkan peralatan dapur khususnya. Pada pembuatan sabun ini menggunakan surfaktan Sodium louryl sulfate (SLS) dan dengan berbagi macam uji. Metode pembuatan sabun dengan menggunakan cold procces. Sodium louryl sufate adalah surfaktan yang murah dan biasa digunakan dalam pembuatan sabun cair pencuci piring. Stabilitas busa yang diperoleh dari hasil ini sebesar $0.14 \%$, nilai $\mathrm{pH}$ yang stabil $\mathrm{pH} 7$, bahan yang tidak larut dalam etanol sebannyak 0,345 gr dan sesuai dengan syarat mutu sabun SNI 2588-2017 dan layak digunakan, dan untuk uji aktivitas bakteri Esherichia coli dengan ekstrak daun sirih daya hambat yang terbentuk dari semua konsentrasi $15 \mathrm{ml}, 30 \mathrm{ml}, 45 \mathrm{ml}$ setelah perlakuan selama 24 jam.

\section{ABSTRACT}

In a modern life, the use of soap for the household is very much, including dish soap, liquid dish soap is a staple that is needed to clean kitchen utensils in particular. Soap is a cleaning agent made based on the saponification reaction between potassium or sodium bases and fatty acids (oils). In making soap this time using the surfactant Sodium louryl sulfate (SLS) and with various kinds of tests. The method of making soap using cold processes. Sodium louryl sulfate is a very common surfactant used in the manufacture of dishwashing liquid soap. The foam stability obtained from these results is $0.14 \%$, a stable $\mathrm{pH}$ value is $\mathrm{pH} \mathrm{7,} \mathrm{the} \mathrm{material} \mathrm{is} \mathrm{not} \mathrm{soluble} \mathrm{in} \mathrm{ethanol} \mathrm{as} \mathrm{much} \mathrm{as} 0.345 \mathrm{~g}$ and is in accordance with the quality requirements of SNI 2588-2017 soap and is suitable for use, and to test the activity of Esherichia coli bacteria with extract betel leaf inhibitory power formed from all concentrations of $15 \mathrm{ml}, 30 \mathrm{ml}, 45$ $\mathrm{ml}$ after treatment for 24 hours it can be concluded that the greater the concentration, the greater the inhibitory power formed 


\section{PENDAHULUAN}

Salah satu jenis sabun yang cukup diminati adalah sabun cair. Permintaan sabun cair cendrung mengalami peningkatan dari tahun ke tahun. Hal ini disebabkan karena sabun cair memiliki beberapa keunggulan, yaitu lebih praktis, higienis dan ekonomis (Watkinson, 2000). Sabun adalah bahan yang digunakan untuk mencuci, baik pakaian, perabotan, badan, dan lainlain yang terbuat dari campuran alkali (natrium atau kalium hidroksida), dan trigliserida dari asam lemak rantai karbon $\mathrm{C}_{16}$ (Zulkifli dan Estiasih, 2014). Melalui reaksi saponifikasi atau disebut juga reaksi penyabunan pada suhu $80-100{ }^{\circ} \mathrm{C}$.

Bahan yang mengandung kotoran dan minyak, bagian yang bersifat hidrofobik pada sabun akan larut dalam minyak dan mengepung kotoran minyak, sedangkan bagian hidrofilik akan terlepas dari permukaan yang dibersihkan dan terdispersi dalam air sehingga dapat dicuci (Djatmiko dan Widjaja, 1984). Sabun dibuat melalui proses saponifikasi lemak minyak dengan larutan alkali membebaskan gliserol. Bahan-bahan pembuatan sabun yang digunakan terdiri dari bahan pendukung, yaitu pewarnaan dan fragrance (pewangi) serta bahan utama. Bahan tersebut digunakan untuk meningkatkan nilai dan kualitas produk sabun. Jenis sabun yang sering dikenal, yaitu sabun padat (batangan) dan sabun cair (Hambali dkk., 2005 dan Kiswandono dkk., 2020). Metode pembuatan sabun berdasarkan suhu yang digunakan terdiri dari metode proses dingin (cold process) dan proses panas (hot process) (Asnani dkk., 2020; Mabrouk dkk., 2005). Perbedaan kedua proses tersebut terletak pada ada atau tidaknya proses pemanasan setelah reaksi penyabunana terjadi. Metode panas memerlukan waktu hanya 60 menit. Pemanasan bertujuan untun mempercepat penghilangan sisa alkali sehingga mempersingkat waktu curing. Sementara, metode dingin memerlukan waktu curing dua sampai empat pekan.

Kandungan zat-zat yang terdapat pada sabun juga bervariasi sesuai dengan sifat dan jenis sabun. Larutan alkali yang digunakan dalam pembuatan sabun bergantung pada jenis sabun tersebut. Proses pembuatan sabun (reaksi saponifikasi) merupakan proses kimia. Analisis alkali bebas merupakan residu yang tidak bereaksi pada pembentukkan sabun. Alkali bebas memiliki kecenderungan semakin menurun akibat lama pengadukan dan akibat rasio air/sabun. Hal ini akibat adanya reaksi alkali dengan asam-asam lemak yang terdapat pada minyak hasil pemurnian sehingga reaksi penyabunan semakin sempurna, yang berdampak pada penurunan alkali bebas. Adanya penurunan alkali bebas ini juga disebabkan oleh rasio air/sabun yang ditambahkan, 
karena air dapat menurunkan konsentrasi alkali bebas dalam sabun. Semakin rendah residu alkali bebas semakin dianjurkan untuk menjamin kesempurnaan reaksi penyabunan dan efek antibakteria (Wijana, 2009). Oleh karena itu, pada penelitian ini akan ditentukan alkali bebas, pH, dan uji antibakteri (Fatimah dkk., 2021 dan Dinastuti dkk., 2021).

\section{METODE}

\section{Alat dan Bahan}

Alat-alat yang digunakan meliputi ember, pengaduk, Piknometer, pipet tetes, $\mathrm{pH}$ meter, labu alas bulat, tabung reaksi, alat titrasi, Erlemeyer, mistar.

Bahan yang digunakan meliputi SLS, texapon dan garam serta bahan aditif seperti parfum, pengawet, pengental dan zat pewarna. Air suling, etanol 96\%, batu didih, $\mathrm{HCl} 0,1 \mathrm{~N}$, larutan phenolphtalin, ekstrak daun sirih, Nutrient Broth (NB), Nutrient Agar.

\section{Prosedur}

\section{Tahapan Pembuatan Sabun.}

Larutkan texafon seperlunya dalam wadah lalu ditambah SLS secukupnya sampai tidak ada gumpalan Langkah selanjutnya campurkan $\mathrm{NaCl} 100$ gr sedikit demi sedikit sambil diaduk sampai mengental dan tidak ada gumpalan.

Tahapan penambahan zat aditif adalah sebagai berikut :

a. Parfum, Dosis parfum dapat disesuaikan dengan banyaknya jumlah sabun yang dihasilkan yaitu sebanyak $15 \mathrm{ml}$.

b. Zat pewarna, digunakan untuk membuat produk lebih menarik Kepekatan warna juga dapat disesuaikan dengan selera dan warnanya harus disesuaikan dengan parfum. Penambahan zat aditif kedalam sabun diaduk sampai merata dan pembuatan sabun telah selesai dilakukan. hasil dari pembuatan sabun dapat dilihat pada Gambar 1. 


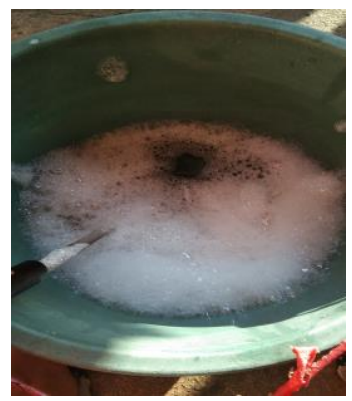

\section{Gambar 1. Hasil Proses pembuatan sabun}

\section{Pemeriksaan berat Jenis}

Piknometer yang sudah bersih dan kering ditimbang (a). Selanjutnya akuades dan sabun cair masing-masing dimasukkan ke dalam piknometer dengan menggunakan pipet tetes. Piknometer ditutup dan dimasukkan ke dalam pendingin sampai suhunya menjadi $25{ }^{\circ} \mathrm{C}$. Kemudian ditimbang berat piknometer yang berisi air (b) dan piknometer yang berisi sabun cair (c).

$$
\text { Berat jenis }=\frac{c-a}{b-a}
$$

Keterangan:

$\mathrm{a}=$ berat piknometer kosong

$\mathrm{b}=$ berat piknometer+air

$\mathrm{c}=$ berat piknometer+sabun cair

\section{Pemeriksaan pH}

Sebanyak $1 \mathrm{ml}$ sabun yang akan diperiksa diencerkan dengan air suling hingga $10 \mathrm{~mL}$. Dimasukkan $\mathrm{pH}$ meter yang telah dikalibrasi ke dalam larutan sabun yang telah dibuat, kemudian ditunggu hingga indikator $\mathrm{pH}$ meter stabil dengan menunjukkan nilai $\mathrm{pH}$ yang konstan.

\section{Pengujian Tinggi Busa}

Dilakukan dengan cara pengocokan. $2 \mathrm{ml}$ sabun cair dimasukkan ke dalam tabung reaksi, kemudian dikocok selama 20 detik dan selanjutnya didiamkan selama 5 menit, kemudian diukur tinggi busa yang terbentuk dengan menggunakan mistar. 


\section{Pengujian Bahan Yang Tidak Larut Dalam Etanol}

Penentuan kadar bahan tak larut dalam etanol Sejumlah $5 \mathrm{ml}$ sampel sabun dilarutkan dengan $200 \mathrm{~mL}$ etanol netral dan dipanaskan dalam rangkaian alat refluks sampai sabun larut seluruhnya. Sampel yang sudah larut disaring menggunakan kertas saring yang sebelumnya dikeringkan dalam oven pada suhu (100-105) ${ }^{\circ} \mathrm{C}$ selama 30 menit. Sampel yang tersisa dalam labu didih dicuci dengan menggunakan larutan etanol sampai bebas terhadap sabun. Residu pada kertas saring dikeringkan dalam oven pada suhu (100-105) ${ }^{\circ} \mathrm{C}$ selama 3 jam kemudian ditimbang.

\section{Pemeriksaan Alkali Bebas}

Pengukuran alkali bebas dilakukan dengan cara titrasi. Sebanyak $5 \mathrm{ml}$ sabun cair dimasukkan kedalam erlemeyer. Selanjutnya ditambahkan $100 \mathrm{ml}$ metanol 96\%. Campuran tersebut dipanaskan hingga mendidih dan selanjutnya dititrasi dengan $\mathrm{HCl} 0,1 \mathrm{~N}$, sampai warna merah muda hilang. Sebagai indikator digunakan larutan phenolphtalin.

\section{Pengujian Viskositas}

Sampel sebanyak $150 \mathrm{ml}$ disiapkan dalam gelas beaker $250 \mathrm{~mL}$, kemudian spindle dengan nomor tertentu dan kecepatan tertentu (rpm) disetel, lalu dicelupkan kedalam sediaan sampai alat menunjukkan nilai viskositas sediaan. Nilai viskositas (cPs) yang ditunjukkan pada alat viskometer Haake merupakan nilai viskositas sediaan.

\section{Uji Aktivitas Antibakteri}

Pembuatan ekstrak daun sirih pada uji aktivasi, daun sirih 200 gr di rebus selama 60 menit.Kemudian buatlah tiga variasi penambahan ekstrak daun sirih yakni $15 \mathrm{ml}, 30 \mathrm{ml}$, dan 45 $\mathrm{ml}$ terhadap sabun dan dilakukan pemerikasaan uji bakteri.

\section{HASIL DAN PEMBAHASAN}

\section{Pemeriksaan Berat Jenis Sabun}

Berat jenis merupakan perbandingan zat terhadap air volume sama yang ditimbang di udara pada suhu yang sama. Sediaan sabun cair ditetapkan bobot jenisnya yaitu 1,01-1,10. 
Pemeriksaan bobot jenis penting untuk dilakukan karena dapat menentukan apakah suatu zat padat dapat bercampur atau tidak dengan zat lainnya, sehingga akan mempermudah dalam formulasi sabun. Pada penelitian ini diperoleh berat jenis sabun sebesar 1,02 gr. Berat jenis ditentukan oleh komponen- komponen yang ada dalam sediaan tersebut. Semakin banyak komponen yang ada dalam sediaan maka fraksi berat semakin tinggi, sehingga bobot jenis juga semakin tinggi.

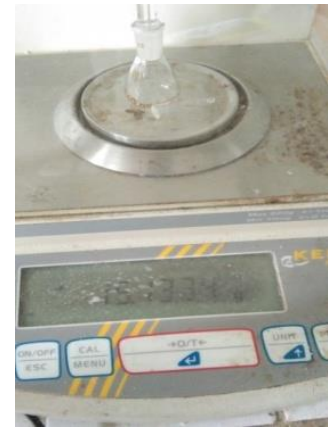

(a)

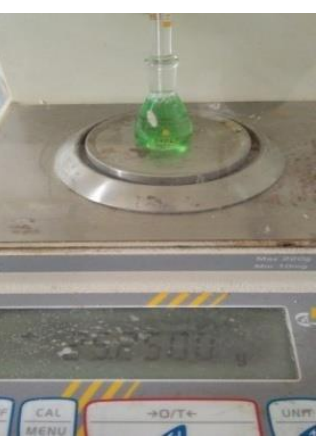

(b)

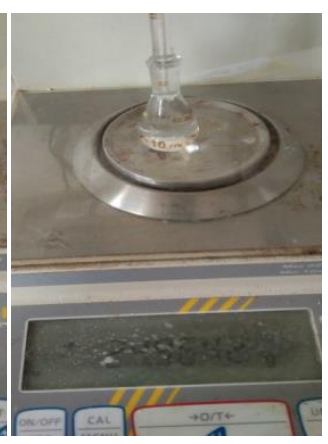

(c)

\section{Gambar 2. (a) Piknometer kosong, (b) Piknometer berisi sabun (c) Piknometer berisi akuades}

\section{Stabilitas Busa}

Pada pengujian stabilitas busa diperoleh Pengujian kestabilan busa bertujuan untuk mengetahui persentase banyaknya busa yang masih tersisa setelah jangka waktu tertentu. Busa adalah sistem koloid dengan fase terdispersi gas dan medium pendispersi zat cair. Fase terdispersi gas biasanya berupa udara atau $\mathrm{CO}_{2}$. Kestabilan busa diperoleh dari adanya surfaktan. Surfaktan memiliki gugus hidrofilik dan hidrofobik. Gugus hidrofilik terikat dengan molekul air, sedangkan gugus hidrofobiknya menuju permukaan larutan dan mengarah ke udara. Ketika larutan air dan surfaktan tersebut diaduk atau dialiri udara maka gelembung udara yang keluar dari badan cairan akan dilapisi oleh lapisan tipis cairan yang mengandung surfaktan dan terbentuklah busa. Stabilitas suatu busa ditentukan oleh elastisitas lapisan tipisnya. Dalam uji stabilitas busa ini pertama sabun diencerkan dengan akuades $10 \mathrm{ml}$ lalu dikocok. Tinggi awal busa $7 \mathrm{~cm}$ dan ditunggu selama 5 menit kemudian diukur kembali tinggi busa ,diperoleh tinggi busa $5 \mathrm{~cm}$. Diperoleh stabilitas busa $0,014 \%$. Tinggi busa akhir dapat dilihat pada Gambar 3 . 


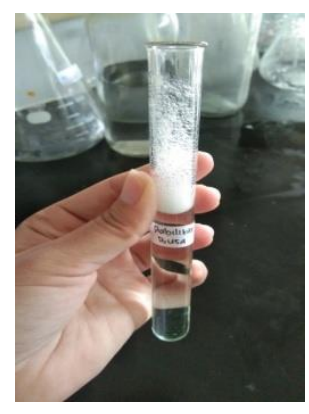

Gambar 3. Tinggi busa akhir

\section{Uji Viskositas}

Pengukuran viskositas sabun cuci piring bertujuan untuk mengetahui besar tahanan yang dihasilkan sabun. Sabun cuci piring mempunyai rentang viskositas 500-20000 cPs. Pengukuran viskositas sediaan sabun cuci piring menggunakan viskometer Haake dengan spindel no. 5 dan kecepatan 30 rpm. Diperoleh nilai viskositas sediaan 13030 cPs.

\section{Analisa Alkali Bebas}

Alkali bebas merupakan alkali yang tidak habis bereaksi dengan asam lemak pada proses pembuatan sabun. Hasil penelitian menunjukkan adanya perubahan warna, yang merupakan salah satu indikator tidak adanya alkali bebas dalam sampel, dari hasil yang ditunjukkan Diperoleh kadar alkali bebas 0,01950 \%. Pada syarat mutu sabun yang baik berdasarkan SNI 3588-2017 adalah $<0.05 \%$ sehingga sabun cuci piring cair yang dihasilkan memenuhi standar alkali bebas yang di persyaratkan SNI.

\section{Pengujian Aktivitas Bakteri}

Hasil pengujian aktivitas bakteri dari ekstrak daun sirih dengan konsentrasi berbeda yakni $15 \mathrm{ml}$, $30 \mathrm{ml}$ dan $45 \mathrm{ml}$ dapat dilihat pada gambar 4. Pada setiap konsentrasi pertama tama dilakukan sterilisasi terhadap alat alat yang akan digunakan alat gelas yang tidak berskala disterilkan dengan oven pada suhu $180{ }^{\circ} \mathrm{C}$ selama 2 jam, sedangkan alat alat gelas berskala disterilkan di autoklaf pada suhu $121^{\circ} \mathrm{C}$ tekanan 2 Atm selama 15 menit. Kemudian pembuatan medium nutrient agar (NA), pembuatan Medium Muller Hilton Agar (MHA),peremajaan kultur bakteri 
dan penyiapan bakteri uji, diperoleh pada saat sabun di uji terhadap bakteri Esherichia coli memperlihatkan bahwa daun sirih memiliki daya hambat.
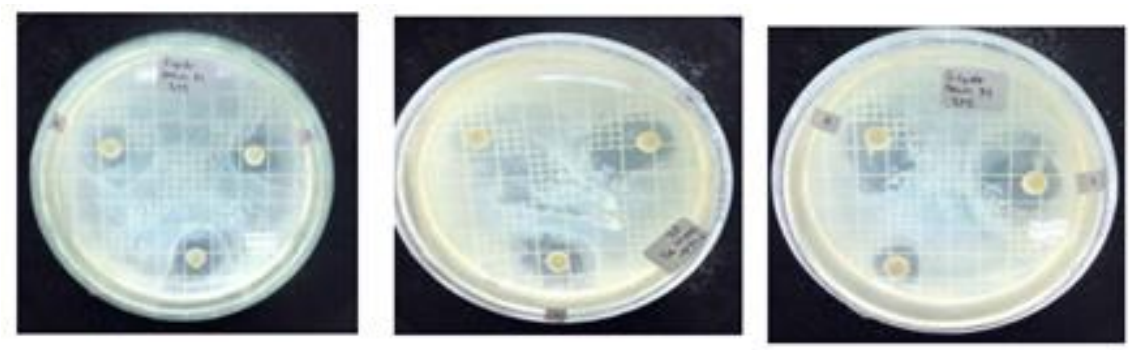

Gambar 4. (a) Sabun dengan konsentrasi 15 ml, (b) Sabun dengan konsentrasi 30 $\mathrm{ml}$, (c) Sabun dengan konsentrasi $45 \mathrm{ml}$

Sabun cair cuci piring dengan bahan aditif ekstrak daun sirih memiliki hasil yang sangat bagus dalam daya hambat pertumbuhan bakteri Esherichia coli. Dimana semakin besar konsentrasi maka semakin besar pula daya hambat yang terbentuk. Terlihat pada tabel 2 bahwa daya hambat semua konsentrasi baik $15 \mathrm{ml}, 30 \mathrm{ml}, 45 \mathrm{ml}$, memiliki daya hambat yang lebih besar dari kontrol positif menandakan bahwa ekstrak daun sirih aktif terhadap penghambatan pertumbuhan bakteri Esherichia coli. Perhatikan tabel.1 berikut, menunjukkan skala perbandingan zona hambat bakteri.

Tabel 1. Tabel perbandingan konsentrasi dan daya hambat bakteri Esherichia coli

\begin{tabular}{lccc}
\hline Perlakuan & \multicolumn{3}{c}{ Jam Ke- } \\
& $\mathbf{6}$ & $\mathbf{1 2}$ & $\mathbf{2 4}$ \\
\hline $\mathbf{A}(\mathbf{1 5} \mathbf{~ m L})$ & $12,77 \mathrm{~mm}$ & $13,23 \mathrm{~mm}$ & $10,77 \mathrm{~mm}$ \\
$\mathbf{B}(\mathbf{3 0} \mathbf{~ m L})$ & $18,67 \mathrm{~mm}$ & $17,60 \mathrm{~mm}$ & $13.84 \mathrm{~mm}$ \\
$\mathbf{C}(\mathbf{4 5} \mathbf{~} \mathbf{m})$ & $20,66 \mathrm{~mm}$ & $20,18 \mathrm{~mm}$ & $14,82 \mathrm{~mm}$ \\
\hline
\end{tabular}

\section{KESIMPULAN}

Sampel yang diperoleh dengan tambahan sodium louryl sulfate memiliki nilai $\mathrm{pH}$ yang stabil $\mathrm{pH}$ 7 yakni, dan jumlah alkali bebas $0,01 \%$ dan bahan yang tidak larut dalam etanol sebannyak 0,345 gr dan sesuai dengan syarat mutu sabun SNI 2588-2017 yang layak digunakan. Pada 
pemeriksaan berat jenis menggunakan piknometer diperoleh hasil 1,02 gr dan stabilitas busa diperoleh hasil 0,14 \% Pengujian aktivitas bakteri Esherichia coli dengan ekstrak penambahan daun sirih diperoleh hasil, pada konsentrasi $15 \mathrm{ml}, 30 \mathrm{ml}, 45 \mathrm{ml}$, dapat diketahui bahwa konsentrasi ekstrak daun sirih sangat berpotensi untuk mencegah pertumbuhan bakteri berbahaya untuk kesehatan..

\section{DAFTAR PUSTAKA}

Asnani, A., Eva, V. Y. D., dan Hartiwi, D., 2019, Transfer Teknologi Produksi Natural SoapBase Untuk Kreasi Sabun Suvenir, Jurnal Pengabdian Kepada Masyarakat (Indonesian Journal of Community Engagement)., 4(2),129.

Djatmiko, B., dan Widjaja, A.P., 1984, Teknologi Lemak dan Minyak Ikan. Bogor : Agro Industri Press. Fateta-IPB.

Hambali, E., Bunasor, T. K., Suryani, A., dan Angga, K. G., 2005, Aplikasi Dietanolamida Dari Asam Laurat Minyak Inti Sawit Pada Pembuatan Sabun Transparan, Journal of Agroindustrial Technology., 15(2), 46-53.

Kiswandono, A. A., Nurhasanah, dan Akmal, J., 2020, Workshop Peningkatan Kemampuan Pembuatan Detergen Cair Sebagai Upaya Mengaktifkan Pengurus PKKDesa Fajar Baru, Aptekmas: Jurnal Pengabdian kepada Masyarakat, Politeknik Negeri Sriwijaya.

Mabrouk, S. T., 2005, Making Usable, Quality Opaque or Transparent Soap, Journal of Chemical Education., 82(10), 1534-37.

Dinastuti, R., Agung, A. K., dan Siti, F., 2021, Formula Sabun Susu Sapi Dengan Penambahan Ekstrak Daun Cengkeh. Analit: Analytical and Environmental Chemistry., 6(01).

Sari, V. I., 2010, Pemanfaatan Stearin Dalam Proses Pembuatan Sabun Mandi Padat. Jurnal Sagu 11.1.

Fatimah, S., Ulfa, N. M., Agung, A. K., 2021, Formula Sabun Susu Sapi Dengan Penambahan Ekstrak Daun Cengkeh. Analit: Analytical and Environmental Chemistry., 6(01).

SNI 3588-2017., 2017, Standar Mutu Sabun Cair, BSN.

Watkinson, C, 2000, Liquid Soap Cleaning Up Share, Inform 11, Champaign, AOCS Press.

Wijana, S., Sumarjo dan Harnawi, T., 2009, Studi pembuatan sabun mandi cair dari daur ulang minyak goreng bekas (Kajian pengaruh lama pengadukan dan rasio air: sabun terhadap kualitas). Jurnal Teknologi Pertanian, 10(1):54-61.

Zulkifli, M., dan Estiasih., 2014, Sabun dari Distilat Asam Lemak Minyak Sawit. Jurnal Pangan dan Agroindustri. 2 (4):170-177 